\title{
Chlorophyll decomposition in Skeletonema costatum: a problem in chlorophyll determination of water samples
}

\author{
Reiko Suzuki $^{1}$ \& Yoshihiko Fujita ${ }^{2 *}$ \\ ${ }^{1}$ Ocean Research Institute, University of Tokyo, Nakano, Tokyo 164, Japan \\ ${ }^{2}$ Department of Cell Biology, National Institute for Basic Biology, Okazaki, Aichi 444, Japan
}

\begin{abstract}
Chlorophyll decomposition during the process of chlorophyll determination currently used for aquatic samples was examined with cultured phytoplankton. Among the phytoplankton tested, chlorophyll a in Skeletonema costatum isolated from Tokyo Bay was found to be extremely unstable. Filtration of cell suspension with gentle suction caused chlorophyll a decomposition mainly to phaeophorbide a. Decomposition of over $40 \%$ of total chlorophyll a occurred resulting an erroneous estimation of phaeopigment proportion in the samples. The decomposition was a result of a high activity of chlorophyllase and acidic material(s), probably organic acid(s), accumulated in the cells. Since the decomposition was found to be initiated by chloroplast damage, we tried to use a hypertonic medium for stabilization of chloroplast structure. Washing of samples with a hypertonic medium $(0.4 \mathrm{M}$ mannitol plus $1 \mathrm{mM} \mathrm{MgCl} 2$ and $3.15 \% \mathrm{NaCl}$ ) just before finish of filtration was found to give $89 \%$ recovery of chlorophyll $a$. However, the effect was not very reproducible.
\end{abstract}

\section{INTRODUCTION}

In ecological studies of aquatic areas, chlorophyll distribution has been regarded as an important index for estimation of phytoplankton mass and capacity of primary production. The method for quantitative analysis of this chemical is well-established. Manuals on aquatic ecology (e.g. Vollenweider 1969, Strickland \& Parsons 1972) have recommended a simple method of chlorophyll measurement for this purpose. The method basically consists of (i) collection of phytoplankton cells on filter paper with gentle suction, (ii) acetone extraction with the aid of mechanical disruption or soaking in cold acetone, and (iii) spectrophotometric or fluorometric measurement. The method currently used has been slightly modified by different research groups to avoid chlorophyll decomposition during the measuring process, e.g. filtration of the samples after $\mathrm{MgCO}_{3}$ addition to protect from phaeopigment formation (cf. Yanagi \& Koyama 1971, Strickland \& Parsons 1972), extraction with absolute acetone to kill chlorophyllase activity (cf. Jeffrey 1974). However, the basic procedure is the same in collection

- Addressee for correspondence of test material from waters and in extraction of chlorophyll without heating. These methods for extraction have been believed to be safe from chlorophyll decomposition. The pigment composition in samples obtained by these methods has been used as an index of the physiological state of phytoplankton (Yanagi \& Koyama 1971, Jensen \& Sakshaug 1973, Jeffrey 1974, Gieskes et al. 1978, Hallegraeff 1981) and grazing action of zooplankton (Jeffrey 1974, Shuman \& Lorenzen 1975, Hallegaeff 1981).

Chlorophylls in vitro are not necessarily stable. Photobleaching of chlorophylls in broken cells (Moreth \& Yentsch 1970), or chlorophyllase action (Barett \& Jeffrey 1964, 1971) are examples. As a first step in the chemical study of chlorophylls in marine samples, we re-examined the method currently used for chlorophyll determination and found that chlorophyll $a$ in Skeletonema costatum isolated from Tokyo Bay is considerably unstable; a marked decomposition of chlorophyll $a$ to phaeophorbide a via chlorophyllide a occurred during the filtration process using gentle suction. In this paper, we report the results obtained from analysis of this chlorophyll decomposition and discuss a possible way of protection from such artificial decomposition. 


\section{MATERIALS AND METHODS}

Algal cultures. The tests were made with the marine diatoms Chaetoceros socialis, isolated from Sagami Bay, and Skeletonema costatum, isolated from Tokyo Bay and with the dinoflagellate Prorocentrum minimum, isolated from Tokyo Bay; the latter 2 were originally isolated by Dr T Ishimaru (Ocean Research Institute, University of Tokyo) and kindly supplied by him. Cells were grown in the $\mathrm{f}$ medium of Guillard \& Ryther (1962) at half nutrient strength at $18^{\circ} \mathrm{C}$. Air containing $0.5 \% \mathrm{CO}_{2}$ was continuously supplied, as was illumination with fluorescent light $\left(6.0 \mathrm{Wm}^{-2}\right.$ for $C$. socialis and $S$. costatum, and $8.0 \mathrm{Wm}^{-2}$ for $P$. minimum). Cells at the late exponential growth phase were used for all experiments.

Cell harvesting and chlorophyll extraction. Cells were collected from cultures in 2 ways: (i) cell suspensions were filtered through a Whatman GF/C filter paper with gentle suction to collect cells on the filter paper (we will call this treatment 'Filtration'), and (ii) cell suspensions were centrifuged at $2000 \times \mathrm{g}$ for 5 min, and cells collected as pellets ('Centrifugation'). Chlorophyll extraction with acetone was also made in 2 ways: (i) repeated extraction at $65^{\circ} \mathrm{C}$ for 2 min ('Heat') and (ii) grinding with acetone in a glass mortar below $25^{\circ} \mathrm{C}$ ('Grinding'). After removing cell and glass fiber debris, the acetone extracts were used for spectrophotometry and chromatographic analysis.

Chromatographic analysis. Extracts were concentrated with a flash evaporator at $25^{\circ} \mathrm{C}$ in the dark. Evaporation was generally completed within $5 \mathrm{~min}$. For separation of chlorophyll $a$ and phaeophytin $a$, paper chromatography with a solvent system of petroleum ether containing $1.35 \% \mathrm{n}$-propanol was used. Rf values for chlorophyll $a$ and phaeophytin $a$ were 0.75 and 0.90 , respectively. Those of chlorophyllide $a$ and chlorophyll $c$ were as low as 0.1 . Thin layer chromatography of reverse phase was used for phytol- free pigments. Pigments were separated by a Merk $\mathrm{MCK}_{18}$ plate with a solvent system of methanol/ acetone/water $(20: 4: 3$ in volume). Rf values of chlorophyllide $a$, phaeophorbide $a$ and chlorophyll $c$ were $0.7,0.4$ and 0.8 , respectively; chlorophyll $a$ and phaeophytin a remained at the starting point. Each pigment was quantitatively eluted from chromatograms by aqueous acetone $(80 \%)$.

Spectrophotometry. Absorption spectra of pigment samples in acetone were measured by a Shimadzu UV 200 spectrophotometer at room temperature. Pigment concentration was calculated by using absorption coefficients reported by Mackinney (1941) for chlorophyll a and phaeophytin $a$, and by Jeffrey (1972) for chlorophyll c. For estimation of chlorophyllide $a$ and phaeophorbide $a$, the values for chlorophyll $a$ and phaeophytin a were used, respectively.

\section{RESULTS AND DISCUSSION}

\section{Chlorophyll decomposition during extraction}

The Grinding treatment is a likely source of chlorophyll decomposition. We examined this possibility first, with extracts from 3 phytoplankton species. Cells were collected by Centrifugation, and extraction was made with acetone of various concentrations. Cells were ground with a small piece of GF/C filter paper for $60 \mathrm{~s}$ at room temperature. Results are presented in Table 1. In each case, the experiment was repeated 3 times. Grinding for a short time did not cause any appreciable decomposition in the case of Prorocentrum minimum; a small amount of decomposed components was found in Chaetoceros socialis. The Grinding treatment seems to be safe in these phytoplankton. However, a large amount of chlorophyllide $a$ and phaeophorbide $a$ was found in the extract of Skeletonema costatum. In the extreme

Table 1. Chlorophyll a decomposition during grinding extraction in various acetone concentrations. Cells were collected by Centrifugation, and chlorophylls were extracted by Grinding at room temperature. For details of experiments, see text

\begin{tabular}{|lcccc|}
\hline Organism & Acetone concentration (\%) & Chlorophyll $a$ & $\begin{array}{c}\text { Relative content (\%) of } \\
\text { Chlorophyllide a }\end{array}$ & Phaeophorbide $a$ \\
\hline Skeletonema & 100 & $73.4 \pm 10.4$ & $15.9 \pm 1.5$ & $10.7 \pm 2.3$ \\
costatum & 80 & $52.8 \pm 6.4$ & $46.9 \pm 13.5$ & $0.3 \pm 0.03$ \\
& 50 & $35.6 \pm 4.3$ & $59.8 \pm 5.9$ & $4.6 \pm 0.4$ \\
Chaetoceros & 100 & $98.7 \pm 0.7$ & $1.3 \pm 0.2$ & 0 \\
socialis & 80 & $99.2 \pm 2.8$ & $0.8 \pm 0.3$ & 0 \\
Prorocentrum & 50 & $98.2 \pm 1.2$ & $1.8 \pm 0.6$ & 0 \\
minimum & 100 & 100.0 & 0 & 0 \\
& 80 & 100.0 & 0 & 0 \\
\end{tabular}


case, almost $65 \%$ of chlorophyll a was found as decomposition products. The major product was chlorophyllide a. Phaeophytin a was insignificant. Since the occurrence of decomposition products depended on the acetone concentration, such pigments are probably not present in the original samples, but are formed by chlorophyllase action during Grinding. Jeffrey (1974) and Riper et al. (1979) reported that chlorophyll extraction with absolute acetone can kill chlorophyllase in the sample. However, chlorophyllide $a$ and phaeophorbide a occurred even in extraction with absolute acetone. The killing action is not necessarily sufficient in this case. Occurrence of chlorophyllide a in extracts from C. socialis also seems to depend on the acetone concentration. It may again be an artificial product due to chlorophyllase action.

As shown in Table 2, extracts by the Heat treatment contained very small amount of chlorophyllide $a$, while a large amount of decomposed pigments occurred in the extracts by Grinding. Decomposition also depended on the temperature during Grinding. Cell disruption without killing chlorophyllase must be a primary cause of chlorophyll decomposition. The cell disruption probably first induced chlorophyllase activation; phaeopigment formation will then occur. To confirm this idea, we examined the effect of cell disruption by sonication. A dense cell suspension (equivalent to $33 \mu \mathrm{g}$ chlorophyll $\mathrm{a} \mathrm{ml}^{-1}$ ) was sonicated for 1 min at $0^{\circ} \mathrm{C}$. Pigments were extracted from the sonicates by Heat treatment. Table 3 compares pigment compositions before and after sonication. Occcurrence of decomposed pigments was found only in the samples after sonication as expected.

\section{Chlorophyll decomposition during filtration}

In most cases of chlorophyll determination of water samples, phytoplankton cells in water are first collected on a glass-fiber or membrane filter with gentle suction. During filtration, cells placed on the filter will suffer from mechanical destruction due to being pressed onto the filter surface. Such an effect will be especially strong on drying the filter after filtration. This effect was examined for Skeletanema costatum by comparing pigment compositions in cell samples collected by Filtration and by Centrifugation. Pigments were extracted by Heat, which is safe from chlorophyll decomposition (cf. Table $2 \& 3$ ). Table 4 clearly indicates that Filtration also causes chlorophyll decomposition. The cell sample collected by Centrifugation contained only a small amount of decomposed pigment (chlorophyllide $a, 5 \%$ ), while more than $40 \%$ of chlorophyll a was decomposed in the samples collected by Filtration. Filtration was finished within $15 \mathrm{~s}$ in this case, and extraction made immediately afterwards. Decomposition progressed further when the samples were left at room temperature in the dark. After $20 \mathrm{~min}$, the chlorophyll a content was reduced to $16 \%$. An $\mathrm{MgCO}_{3}$ layer placed on the filter surface did not improve the result (data not shown).

Results indicate that chlorophyll decomposition is more marked in Filtration than in the Grinding process. The main product was phaeophorbide $a$, similar to the case of cell sonication (Table 3), but different from the case of Grinding (Tables 1 \& 2) where the main product was chlorophyllide $a$. The decomposition products seem to depend on the cell density during cell

Table 2. Skeletonema costatum. Chlorophyll a decomposition during Heat and Grinding extraction methods. Cells were collected by Centrifugation, and chlorophylls extracted by hot acetone $\left(65^{\circ} \mathrm{C}, 2 \mathrm{~min}\right)$ for Heat, and for Grinding, by grinding in a glass mortar with absolute acetone at respective temperature. For details of experiments, see text

\begin{tabular}{|c|c|c|c|}
\hline Method & Chlorophyll a & $\begin{array}{l}\text { lative content (\%) } \\
\text { Chlorophyllide }\end{array}$ & Phaeophorbide a \\
\hline Heat & $95.2 \pm 7.8$ & $4.9 \pm 0.4$ & 0 \\
\hline Grinding, $0^{\circ} \mathrm{C}$ & $73.4 \pm 10.4$ & $15.9 \pm 1.5$ & $10.7 \pm 2.3$ \\
\hline Grinding, $30^{\circ} \mathrm{C}$ & $42.9 \pm 10.4$ & $21.7 \pm 4.4$ & $35.3 \pm 17.5$ \\
\hline
\end{tabular}

Table 3. Skeletonema costatum. Chlorophyll a decomposition and cell destruction. Cells were collected by Centrifugation and

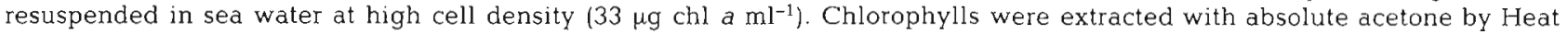
without sonication for 'Intact', and after sonication for $1 \mathrm{~min}$ at $0^{\circ} \mathrm{C}$ for 'Broken'. For details of experiments, see text

\begin{tabular}{|c|c|c|c|c|}
\hline \multirow[t]{2}{*}{ Cell condition } & \multicolumn{4}{|c|}{ Relative content $(\%)$ of } \\
\hline & Chlorophyll a & Chlorophyllide $a$ & Phaeophytin $a$ & Phaeophorbide $a$ \\
\hline Intact & 100 & Trace & 0 & Trace \\
\hline Broken & $20 \pm 1.7$ & $6.8 \pm 0.86$ & $9.0 \pm 0.81$ & $65 \pm 16$ \\
\hline
\end{tabular}


Table 4. Skeletonema costatum. Chlorophyll a decomposition and cell collection. For Centrifugation, cells were collected by Centrifugation, and chlorophylls were extracted by Heat. For Filtration, cells were collected on the GF/C by filtration with gentle suction, and chlorophylls extracted with absolute acetone by Heat either immediatedly after filtration (Filtration, 0 min), or after $20 \mathrm{~min}$ at room temperature in the dark (Filtration, $20 \mathrm{~min}$ ). For details of experiments, see text

\begin{tabular}{|lcccc|}
\hline Collection method & & \multicolumn{2}{c|}{ Relative content (\%) of } \\
& Chlorophyll a & Chlorophyllide $a$ & Phaeophytin a & Phaeophorbide a \\
\hline Centrifugation & $95.0 \pm 1.9$ & $5.0 \pm 1.5$ & 0 & 0 \\
Filtration, 0 min & $57.0 \pm 4.7$ & $11.8 \pm 5.0$ & $2.2 \pm 1.2$ & $29.0 \pm 3.3$ \\
Filtration, 20 min & $15.8 \pm 7.0$ & 0 & $7.7 \pm 2.6$ & $76.5 \pm 2.3$ \\
\hline
\end{tabular}

disruption; at high cell density, phaeophorbide $a$ is mainly formed, and at low density, chlorophyllide a. Sonic treatment was made at high cell density. Cell breakage during Filtration must occur after the cells have been pressed on to the filter, and are thus at very high density. On the other hand, cells were disrupted at low density in the Grinding treatment. The relation between phaeopigment formation and cell density suggests that phaeopigment formation is induced by an acidic material accumulated in the cells, probably organic acid(s). In Grinding, such acidic material would be diluted by the medium immediately after cell breakage.

Occurrence of phaeophorbide a but not phaeophytin a indicates that phaeopigment formation occurs after chlorophyllide $a$ is formed. Since chlorophyllase is present in the chloroplasts (Ardao \& Vennesland 1960), chloroplast breakage, and thus disorganization of thylakoid, will induce activation of chlorophyllase. Chlorophyllase will attack chlorophyll-protein complexes in the thylakoid membranes and form chlorophyllide a which is no longer bound tightly to the protein complexes. The chlorophyllide a released will then suffer from the acidic environment caused by acidic material present at the outside of chloroplasts, and will be converted to phaeophorbide a. Therefore, chlorophyll decomposition in Skeletonema costatum may be characterized by an active chlorophyllase and by an accumulation of acidic material in the cells.

The phaeopigment proportion of samples is an important index for aquatic ecology. Chlorophyll decomposition observed for Filtration is a serious problem, if the phytoplankton in the water samples has a similar nature to Skeletonema costatum. However, in Grinding, only a small amount of phaeopigment was formed, so this process is fairly safe in this sense. A high chlorophyllase activity has been found in many diatoms (Barret \& Jeffrey 1964, 1971). Phaeopigment formation observed here may not be specific to $S$. costatum.

\section{Protection of chlorophyll decomposition by hypertonic medium}

Chloroplasts may be kept unbroken even in vitro when the cells are broken in a hypertonic or isotonic medium such as those used for isolation of intact chloroplasts from higher plants (Cockburn et al. 1968). With this idea, we examined the effect of hypertonic treatment on chlorophyll decomposition during Filtration. It is not practical to make the whole sample hypertonic by adding sugar or polyalcohol before filtration. We tried to wash the samples on the filter

Table 5. Skeletonema costatum. Effect of hypertonic washing on chlorophyll a decomposition. Cells were collected by Fultration with or without washing by the respective hypertonic medium, and chlorophylls were extracted with absolute acetone by Heat Control was by Centrifugation cell collection and Heat extraction. For details of experiments, see text

\begin{tabular}{|c|c|c|c|c|}
\hline \multirow[t]{2}{*}{ Treatment } & \multicolumn{4}{|c|}{ Relative content (\%) of } \\
\hline & Chlorophyll a & Chlorophyllide $a$ & Phaeophytin $a$ & Phaeophorbide a \\
\hline \multicolumn{5}{|l|}{ Filtration, $0 \mathrm{~min}$} \\
\hline without washing & $66.7 \pm 4.7$ & $14.0 \pm 0.7$ & $9.3 \pm 1.0$ & $10.0 \pm 1.3$ \\
\hline washing, Medium I & $75.3 \pm 9.0$ & $17.5 \pm 0.6$ & 0 & $7.1 \pm 1.3$ \\
\hline washing, Medium II & $90.0 \pm 2.7$ & $4.3 \pm 0.9$ & 0 & $4.9 \pm 1.0$ \\
\hline \multicolumn{5}{|l|}{ Filtration, 5 min } \\
\hline without washing & $37.7 \pm 8.5$ & $7.9 \pm 1.9$ & $21.1 \pm 1.9$ & $33.1 \pm 2.0$ \\
\hline washing, Medium II & $79.4 \pm 10.2$ & $6.4 \pm 1.6$ & 0 & $140 \pm 1.6$ \\
\hline Control & $94.0 \pm 0.7$ & $3.7 \pm 1.0$ & 0 & $2.5 \pm 0.9$ \\
\hline
\end{tabular}


paper with the hypertonic medium just before the finish of filtration. As the washing medium, $0.4 \mathrm{M}$ mannitol solution (I) or $0.4 \mathrm{M}$ mannitol plus $1 \mathrm{mM}$ $\mathrm{MgCl}_{2}$ and $3.5 \% \mathrm{NaCl}$ solution (II) was tested. Results are shown in Table 5. Medium I was not very effective for protecting the sample against chlorophyll decomposition. However, washing with Medium II markedly reduced chlorophyll decomposition; only $5 \%$ of chlorophyll a was decomposed to phaeopigment. The effect persisted for at least 5 min after filtration. Results confirm the above idea and indicate that hypertonic washing is one method of protecting samples from chlorophyll decomposition.

However, the effect is not necessarily perfect and reproducible. The medium may be too simple for the purpose. A more sophisticated composition will be required, similar to the case for isolation of Class I type chloroplasts from higher plants (cf. Cockburn et al. 1968, Reeves \& Hall 1980). Another problem is the occurrence of cell breakage during filtration; it must occur for the cells placed on the filter surface, and may reduce the reproducibility of the protecting effect. Further improvement is necessary before putting the method in practice.

Acknowledgements. This work was partly supported by a Grant-in-Aid for Scientific Research from the Ministry of Education, Science and Culture, Japan. We wish to express our thanks to Dr. T. Ishimaru for his kind supply of phytoplankton strains.

\section{LITERATURE CITED}

Ardao, C., Vennesland, B. (1960). Chlorophyllase activity of spinach chloroplastin. Pl. Physiol. 35: 368-371

Barret, J., Jeffrey, S. W. (1964). Chlorophyllase and formation of an atypical chlorophyllide. Pl. Physiol. 35: 368-371

Barret, J., Jeffrey, S. W. (1971). A note on the occurrence of chlorophyllase in marine algae. J. exp. mar. Biol. Ecol. 7 : 255-262

Cockburn, W. Walker, D. A., Baldry, C. W. (1968). The isola- tion of spinach chloroplasts in pyrophosphate media. Pl. Physiol. 43: 1415-1418

Gieskes, W. W., Kraay, G. W., Tikssen, S. B. (1978). Chlorophylls and their degradation products in the deep pigment maximum layer of the tropical north Atlantic. Neth. J. Sea Res. 12; 195-204

Guillard, R. R. L., Ryther, J H. (1962). Studies of marine planktonic diatoms I. Cyclotella nana Hustedt, and Detonula confervacea (Cleve) Gran. Can. J. Microbiol. 8: 229-239

Hallegraeff, G. M. (1981). Seasonal study of phytoplankton pigments and species at a coastal station off Sydney: importance of diatoms and the nanoplankton. Mar Biol. 61: $107-108$

Jeffrey, S. W. (1972). Preparation and some properties of crystalline chlorophyll $c_{1}$ and $c_{2}$ from marine algae. Biochim. Biophys. Acta 279: 15-33

Jeffrey, S. W (1974). Profiles of photosynthetic pigments in the ocean using thin layer chromatography. Mar. Biol. 26: $101-110$

Jensen, A., Sakshaug, E. (1973). Studies on the phytoplankton ecology of the Trondheim fjord, 2. Chloroplast pigments in relation to abundance and physiological state of the phytoplankton, J. exp. mar Biol. Ecol. 11. 137-155

Mackinney, G. (1941). Absorption of light by chlorophyll solution. J. biol. Chem. 140: 315-322

Moreth, C. M., Yentsch, C. S. (1970). The role of chlorophyllase and light in the decomposition of chlorophyll from marine phytoplankton. J. exp. mar. Biol. Ecol. 4: 238-249

Reeves, S. G., Hall, D. O. (1980). Higher plant chloroplasts and grana: general preparative procedures. In: San Pietro A. (ed.) Methods in enzymology, Vol. 69, Photosynthesis and nitrogen fixation. Adacemic Press, New York, p. 85-94

Riper, D. M., Owens, T G., Falkowski, P. G. (1979). Chlorophyll turnover in Skeletonema costatum, a marine plankton diatom. Pl. Physiol. 64: 49-54

Shuman, F. R., Lorenzen, C. J. (1975). Quantitative degradation of chlorophyll by a marine herbivore. Limnol. Oceanogr 20: 580-586

Strickland, J. D. H., Parsons, T R. (1972). A practical handbook of seawater analysis. Bull. Fish. Res. Bd Can. 167

Vollenweider, R. A. (1969). A manual on methods for measuring primary production in aquatic environments, IBP Handbook, No. 12, Blackwell, Oxford

Yanagi, K., Koyama, T (1971). Thin layer chromatographic method for determination of plant pigments in marine particulate matter, and ecological significance of the result. Geochemical J. 5: 23-37 